\title{
Evaluation of performance of hybrid photolysis-DCMD and photocatalysis- -DCMD systems utilizing UV-C radiation for removal of diclofenac sodium salt from water
}

\author{
Sylwia Mozia*, Dominika Darowna, Jacek Przepiórski, Antoni W. Morawski \\ West Pomeranian University of Technology, Szczecin, Institute of Chemical and Environment Engineering, Department of Water \\ Technology and Environment Engineering, ul. Pułaskiego 10, 70-322 Szczecin, Poland \\ "Corresponding author: sylwia.mozia@zut.edu.pl
}

\begin{abstract}
The removal of a non-steroidal anti-inflammatory drug (NSAID) diclofenac sodium salt (DCF, $\mathrm{C}_{14} \mathrm{H}_{10} \mathrm{Cl}_{2} \mathrm{NNaO}_{2}$ ) from water in two hybrid systems coupling photolysis or photocatalysis with direct contact membrane distillation (DCMD) is presented. A UV-C germicidal lamp was used as a source of irradiation. The initial concentration of DCF was in the range of $0.005-0.15 \mathrm{mmol} / \mathrm{dm}^{3}$ and the $\mathrm{TiO}_{2}$ Aeroxide ${ }^{\circledR} \mathrm{P} 25$ loading (hybrid photocatalysis-DCMD) ranged from 0.05 to $0.4 \mathrm{~g} / \mathrm{dm}^{3}$. Regardless of the applied hybrid system and the initial concentration of DCF, the model drug was completely decomposed within $4 \mathrm{~h}$ of irradiation or less. Mineralization was less efficient than photodecomposition. In case of the hybrid photolysis-DCMD process the efficiency of TOC degradation after $5 \mathrm{~h}$ of irradiation ranged from 27.3-48.7\% depending on the DCF initial concentration. The addition of $\mathrm{TiO}_{2}$ allowed to improve the efficiency of TOC removal. The highest degradation rate was obtained at $0.3 \mathrm{gTiO}_{2} / \mathrm{dm}^{3}$. During the process conducted with the lowest DCF initial concentrations $\left(0.005-0.025 \mathrm{mmol} / \mathrm{dm}^{3}\right)$ a complete mineralization was obtained. However, when higher initial amounts of DCF were used $\left(0.05-0.15 \mathrm{mmol} / \mathrm{dm}^{3}\right)$, the efficiency of TOC degradation was in the range of $82.5-85 \%$. The quality of distillate was high regardless of the system: DCF was not detected, TOC concentration did not exceeded $0.7 \mathrm{mg} / \mathrm{dm}^{3}\left(1.9 \mathrm{mg} / \mathrm{dm}^{3}\right.$ in permeate) and conductivity was lower than $1.6 \mu \mathrm{S} / \mathrm{cm}$.
\end{abstract}

Keywords: photocatalytic membrane reactor, direct contact membrane distillation, photolysis, photocatalysis, diclofenac sodium salt.

\section{INTRODUCTION}

Non-steroidal anti-inflammatory drugs (NSAIDs) are emerging environmental pollutants being more and more often identified in the aquatic ecosystems. Spent pharmaceuticals and their metabolites enter the sewage systems posing a risk to the environment. Since the effectiveness of biodegradation of the drugs is limited, wastewater treatment facilities are considered to be the main source of the contamination of surface waters ${ }^{1}$. NSAIDs can be toxic or genotoxic. Activated sludge is endangered by the toxicity of the pharmaceuticals, which can affect the removal of all pollutants in the wastewater plant. Pharmaceuticals in wastewater are often detected in the ng- $\mu \mathrm{g} / \mathrm{dm}^{3}$ range. Even if these quantities may not pose much acute risk to the organisms, it could lead to many synergistic effects with other pharmaceuticals present in the aquatic environment and be a threat to the environment. Residues of the drugs may also reach the sources of drinking water ${ }^{2}$.

One of the most frequently detected NSAID in water is diclofenac (DCF, (2-(2,6-dichloroanilino)phenylacetic acid, $\mathrm{C}_{14} \mathrm{H}_{11} \mathrm{Cl}_{2} \mathrm{NO}_{2}$ ), used as an analgesic, antiarthritic and antirheumatic medicine ${ }^{3}$. In many countries it is often sold without prescription. Diclofenac is rapidly decomposed by natural sunlight to many products. But some of the photoproducts show much higher toxicity than the parent drug $^{4}$, and since they are not mineralized by solar irradiation they stay in the environment as persistent pollutants ${ }^{5}$. Therefore, to solve all of the above mentioned problems, it is important to find an efficient way for the removal of diclofenac and other NSAIDs from water.
In recent years, advanced oxidation processes (AOPs), such as photolysis, photocatalysis, photo-Fenton, sonolysis, ozonolysis and their combinations are often studied as promising methods of the removal of persistent contaminants ${ }^{6}$, such as pharmaceuticals from water ${ }^{4-5,7-11}$. AOPs effectiveness is based on the generation of highly reactive hydroxyl radicals $(\mathrm{OH} \bullet)$, which could oxidize many organic compounds. Eventually, complete mineralization to $\mathrm{CO}_{2}$, water, and mineral salts can be obtained ${ }^{\mathbf{1 1}}$.

Photocatalytic membrane reactors (PMRs) are hybrid systems coupling photocatalysis with membrane processes. They allow the degradation and mineralization of the contaminants and separation of the photocatalyst to be conducted simultaneously. Membrane acts as a barrier which helps to confine the photocatalyst in the reaction environment ${ }^{12}$. Most of the PMRs described in the literature combine photocatalysis with pressure driven membrane processes, such as: microfiltration $(\mathrm{MF})^{13-15}$, ultrafiltration $(\mathrm{UF})^{16-18}$, or nanofiltration $(\mathrm{NF})^{19}$, but also other techniques, namely dialysis ${ }^{20}$, pervaporation ${ }^{21}$, or membrane distillation ${ }^{22-26}$ have been applied. In case of the pressure driven membrane processes, the particles of a photocatalyst can cause clogging of the membrane pores and therefore fouling is observed. Fouling does not appear in the PMR where direct contact membrane distillation (DCMD) is applied, which results from different transport mechanism compared to the pressure driven membrane techniques ${ }^{12}$.

Direct contact membrane distillation is a process in which the transport through the membrane is caused by the vapor pressure difference on both sides of the membrane and it is not necessary to use a high pressure as a driving force. Through the DCMD membrane 
only the volatile compounds can be transported and non-volatile compounds are retained on the feed side, therefore it is possible to obtain a high quality distillate. However, even if the DCMD alone is a good method of the removal of the non-volatile compounds from water, these compounds still need to be eliminated from the concentrate. The application of the PMRs allows to obtain a clean water (distillate) as a product, and a treated concentrate free of organic pollutants which are removed through the photocatalytic degradation ${ }^{\mathbf{1 2}}$. The PMR utilizing DCMD have already been studied by our group for the removal of azo-dyes ${ }^{17-18,22-23}$ and ibuprofen sodium salt ${ }^{24-26}$ from water.

In the present study we have focused on a comparison of the performance of two hybrid systems coupling DCMD with photolysis or photocatalysis utilizing UV-C irradiation for removal of diclofenac sodium salt from water. The possibility of degradation of the NSAID without application of a photocatalyst, which could possibly reduce the treatment cost, was evaluated. The effect of the initial concentration of the model compound and the $\mathrm{TiO}_{2}$ loading on the decomposition and mineralization of DCF and the quality of the distillate were also investigated.

\section{MATERIALS AND METHODS}

\section{Materials}

Diclofenac sodium salt (DCF, $\mathrm{C}_{14} \mathrm{H}_{10} \mathrm{Cl}_{2} \mathrm{NNaO}_{2}, 318.1$ $\mathrm{g} / \mathrm{mol}$ ) purchased from Sigma Aldrich was used as a model compound. The initial concentration $\left(c_{0}\right)$ of DCF was in the range of $0.005-0.15 \mathrm{mmol} / \mathrm{dm}^{3}$ which corresponded to its total mass in a feed solution of 6.1-183.2 mg. Model solutions were prepared using ultrapure water (Simplicity ${ }^{\mathrm{TM}}$, Millipore). Commercially available $\mathrm{TiO}_{2}$ Aeroxide ${ }^{\circledR}$ P25 (Evonik, Germany) was used as a photocatalyst. The $\mathrm{TiO}_{2} \mathrm{P} 25$ loading ranged from 0.05 to $0.4 \mathrm{~g} / \mathrm{dm}^{3}$.

\section{Experimental setup}

The hybrid photolysis-DCMD and photocatalysisDCMD processes were carried out in a laboratory-scale PMR system with the setup similar to the typical installation for DCMD (Fig. 1). The only modification was incorporation of the flow through photoreactor with an UV-C germicidal lamp (Philips TUV 16W, $\lambda_{\max }=$ $254 \mathrm{~nm}$; UV light intensity: $1.54 \mathrm{~W} / \mathrm{m}^{2}$ ). The process was conducted in a batch mode. The system was equipped with a capillary module containing 9 hydrophobic polypropylene Accurel PP S6/2 membranes with outside/ inside diameters of $\mathrm{d}_{\text {out }} / \mathrm{d}_{\text {in }}=2.6 / 1.8 \mathrm{~mm}$ (Membrana $\mathrm{GmbH}$, Wuppertal, Germany). The nominal pore size of the PP membranes was $0.2 \mu \mathrm{m}$ and the maximum pore size was $\leq 0.65 \mu \mathrm{m}$ (according to the manufacturer). The effective area of the membranes was equal to $0.0127 \mathrm{~m}^{2}$.

During the experiments the feed and distillate temperatures at the inlets of the membrane module were maintained at $63^{\circ} \mathrm{C}$ and $20^{\circ} \mathrm{C}$, respectively. The warm feed and the cold distillate streams flowed in the membrane module in the co-current mode. The flow rate of the feed inside the capillaries was equal to $0.5 \mathrm{~m} / \mathrm{s}$ and the flow rate of the distillate outside of the capillaries was equal to $0.2 \mathrm{~m} / \mathrm{s}$. The maximum permeate flux $\left(\mathrm{J}_{\max }\right)$ measured for pure water amounted to $198 \mathrm{dm}^{3} / \mathrm{m}^{2} \mathrm{~d}$.

At the beginning of the process $3.8 \mathrm{dm}^{3}$ of the feed solution and $0.7 \mathrm{dm}^{3}$ of the distillate (ultrapure water) were poured into the tanks. The feed solution in the feed tank was heated to $60^{\circ} \mathrm{C}$ and in case of the hybrid photocatalysis-DCMD process a defined amount of the photocatalyst was added. After 30 minutes of adsorption in the dark the UV lamp was switched on and the process was started. The hybrid process was conducted for 5 hours. After the defined time of the irradiation the samples of feed and distillate solutions were taken and analyzed. Before the analysis, the samples of the feed solution were filtered though the $0.2 \mu \mathrm{m}$ membrane filters to remove photocatalyst particles.

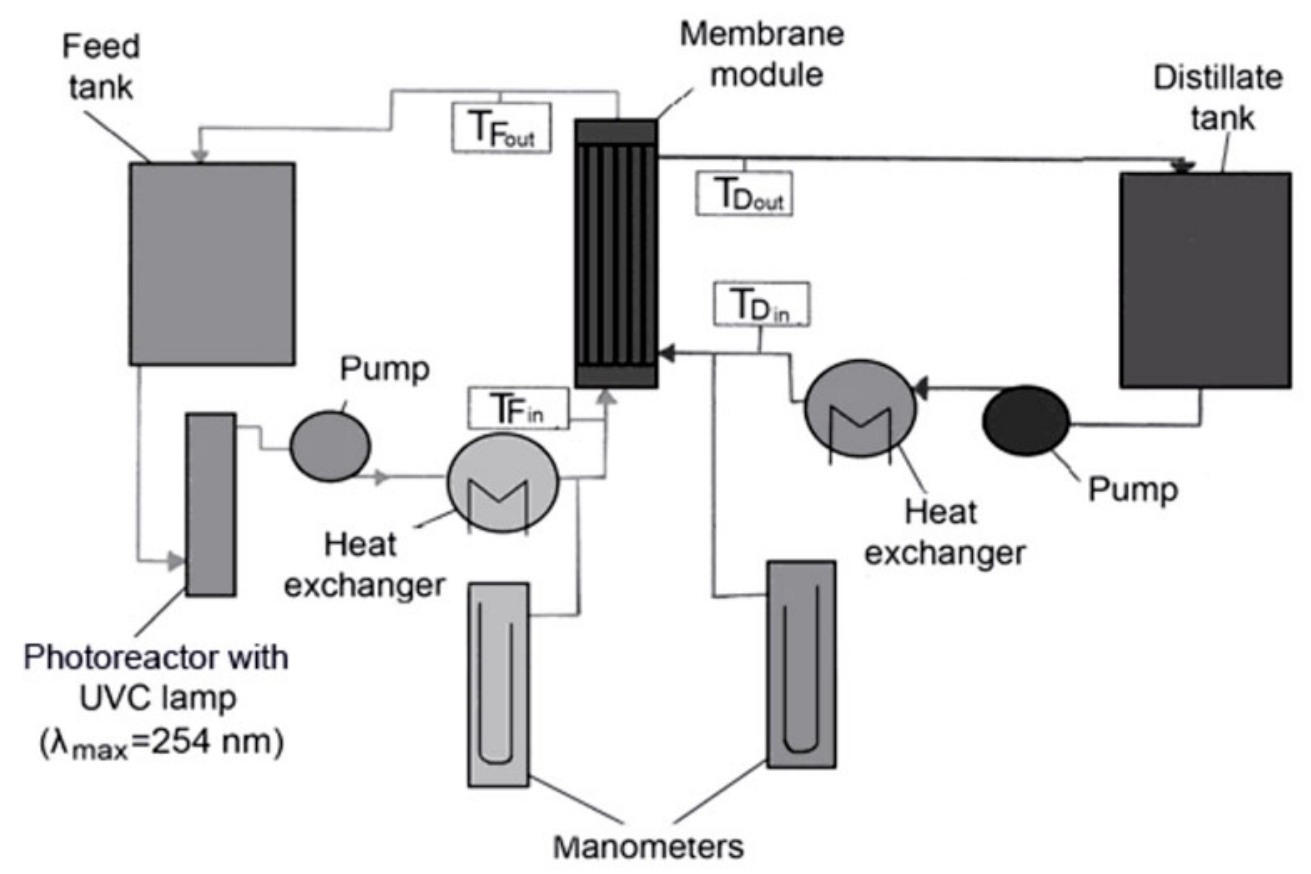

Figure 1. Schematic diagram of the laboratory-scale installation for hybrid photolysis or photocatalysis - DCMD process. $T_{\text {Fin }}, T_{\text {Fout }}$, $\mathrm{T}_{\text {Din }}, \mathrm{T}_{\text {Dout }}$ - thermometers for measuring the temperature at the inlet and outlet of feed and distillate, respectively 
Each experiment was repeated at least twice to confirm the reproducibility of the results. All data points represent the mean values from two repetitions. The experimental errors were less than $10 \%$.

\section{Analytical methods}

DCF concentration was determined using HPLC LaChrom Elite (Hitachi, Japan) equipped with the Chromolith Performance RP-8e 100-4.6 column and $\mathrm{UV} / \mathrm{Vis}$ detector. The mobile phase consisted of $60 \%$ of $20 \mathrm{mmol} / \mathrm{dm}^{3} \mathrm{NaH}_{2} \mathrm{PO}_{4}(\mathrm{pH}=2.6$ adjusted with $\mathrm{H}_{3} \mathrm{PO}_{4}$ ) and $40 \%$ of acetonitrile. Total organic carbon (TOC) concentration was measured using ,multi N/C 2000" analyzer (Analytik Jena, Germany). Conductivity and total dissolved solids (TDS) were measured using Ultrameter $^{\mathrm{TM}}$ 6P (MYRON L COMPANY, USA); pH of the solutions was also monitored.

\section{RESULTS AND DISCUSSION}

\section{Effect of initial concentration of DCF on its removal in the hybrid photolysis - DCMD system}

Photolysis is a process, in which the bond cleavage induced by ultraviolet, visible, or infrared radiation takes place $^{27}$. It was applied for the decomposition of many organic pollutants, including NSAIDs such as diclofenac ${ }^{\mathbf{1 0}}$.

During the first step of the present research the hybrid photolysis - DCMD experiments were conducted. The initial concentration of the model compound ranged from 0.005 to $0.15 \mathrm{mmol} / \mathrm{dm}^{3}$. The permeate flux remained constant during all the experiments and was equal to the pure water flux $\mathrm{J}_{\max }\left(198 \mathrm{dm}^{3} / \mathrm{m}^{2} \mathrm{~d}\right)$.

In the discussion the number of milimoles [mmol] or mass units [mg] were used instead of the concentration units $\left(\left[\mathrm{mmol} / \mathrm{dm}^{3}\right],\left[\mathrm{mg} / \mathrm{dm}^{3}\right]\right)$ in order to overcome the difficulties with the interpretation of the results associated with the decreasing feed volume due to the transport of water and volatile compounds through the membrane, as was discussed elsewhere ${ }^{24}$.

The effect of the initial concentration $\left(c_{0}\right)$ of DCF on its photolytic decomposition in feed solution is shown in Fig. 2. Quantities of DCF in the feed solution were continuously decreasing in time. The highest decrease of DCF concentration was observed during the first 60 minutes of the process (79-96\% of DCF was decomposed, depending on $\mathrm{c}_{0}$ ). Regardless of the initial concentration,

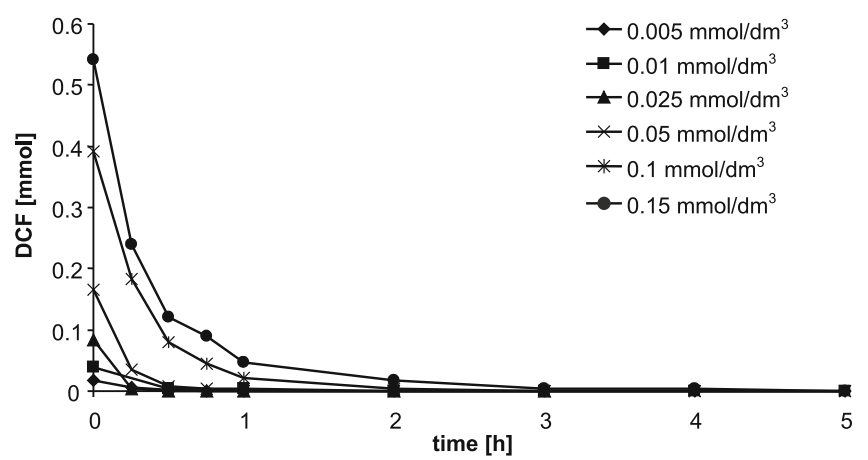

Figure 2. Effect of initial concentration of DCF on the effectiveness of its decomposition in the hybrid photolysis - DCMD process. Initial DCF concentration: $0.005-0.15 \mathrm{mmol} / \mathrm{dm}^{3}$, feed volume: $3.8 \mathrm{dm}^{3}$, reaction temperature: $60^{\circ} \mathrm{C}$
DCF was completely decomposed within less than 4 hours of irradiation.

Even if the decomposition of diclofenac sodium salt is complete, it does not mean that the treated water is free from dangerous contaminants. On the contrary, it was reported $^{4}$ that the toxicity of the reaction mixture was increasing in time of the irradiation as the products of the decomposition, mainly chloroderivatives are more toxic than DCF itself. DCF absorbs radiation in the UV region of the spectrum $\left(\lambda_{\max }=273 \mathrm{~nm}\right)$, close to the spectrum of the UV lamp used in this study $\left(\lambda_{\max }=\right.$ $254 \mathrm{~nm}$ ), therefore the photolysis of DCF can be conducted easily ${ }^{5}$. But the by-products of the photoreaction may have different absorbance spectra, therefore, their decomposition under these conditions might be ineffective. It can be found in literature ${ }^{28}$ that photolysis is an effective method of the removal of diclofenac from water. However, these studies focus only on the decomposition of the model drug alone, without considering the fact that the treated water still contains many toxic by-products of the decomposition. Therefore, in the present research, except from the changes of DCF the TOC amounts in feed were also monitored.

Figure 3 presents the efficiency of mineralization of the model drug during the hybrid photolysis-DCMD process. After $5 \mathrm{~h}$ of the photolysis $27.3-48.7 \%$ of TOC were removed, depending on the DCF initial concentration. The reason why mineralization did not reach $100 \%$ was the presence of some by-products in the reaction mixture which were resistant to UV light. This conclusion is supported by the data of DCF degradation conducted at low $\mathrm{c}_{0}$ (i.e. $<0.25 \mathrm{mmol} / \mathrm{dm}^{3}$ ). In this case, starting from the second hour of irradiation TOC amount remained constant.

Surprisingly, in case of higher initial concentrations of the model contaminant $\left(\mathrm{c}_{0} \geq 0.025 \mathrm{mmol} / \mathrm{dm}^{3}\right)$, the percentage of TOC removal after $1 \mathrm{~h}$ of irradiation was higher than after $5 \mathrm{~h}$ (Fig. 3). It may be associated with a drastic decrease of $\mathrm{pH}$ of the reaction mixture. In the first hour of the photolysis $\mathrm{pH}$ decreased from 5.4 to even 3.9 in case of the highest initial concentration of DCF $\left(0.15 \mathrm{mmol} / \mathrm{dm}^{3}\right)$, whereas in case of the lowest $\mathrm{c}_{0}$ $\left(0.005 \mathrm{mmol} / \mathrm{dm}^{3}\right) \mathrm{pH}$ changed only slightly from 5.3 to 4.9. In subsequent hours of the experiments conducted with lower DCF concentrations $\left(\mathrm{c}_{0} \leq 0.025 \mathrm{mmol} / \mathrm{dm}^{3}\right)$ $\mathrm{pH}$ was almost constant, whereas in case of $\mathrm{c}_{0}$ above

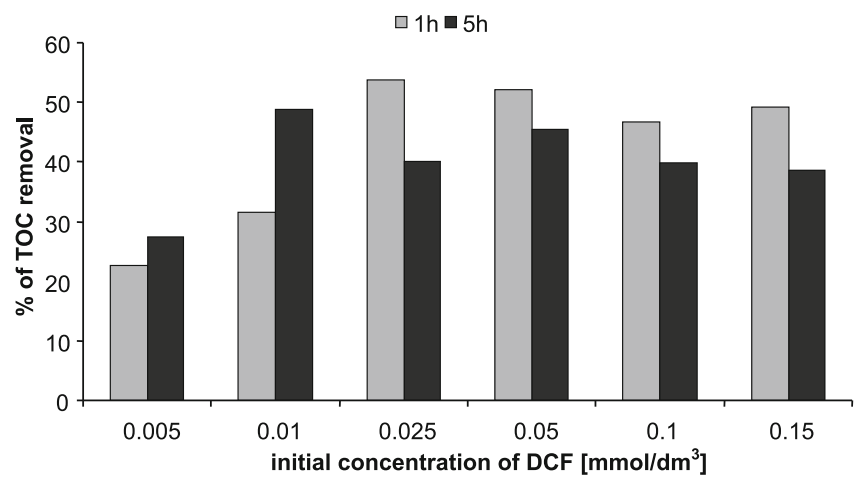

Figure 3. Effect of initial concentration of DCF on the effectiveness of its mineralization in the hybrid photolysis - DCMD system. Initial DCF concentration: $0.005-0.15 \mathrm{mmol} / \mathrm{dm}^{3}$, feed volume: $3.8 \mathrm{dm}^{3}$, reaction temperature: $60^{\circ} \mathrm{C}$ 
$0.025 \mathrm{mmol} / \mathrm{dm}^{3} \mathrm{pH}$ of the solution increased (up to $\mathrm{pH} 4.95$ for $\left.\mathrm{c}_{0}=0.15 \mathrm{mmol} / \mathrm{dm}^{3}\right)$. The decrease of $\mathrm{pH}$ indicates that the photodegradation of the model compound was followed by a formation of some by-products exhibiting acidic properties, such as hydrochloric acid and carboxylic acids. A drastic decrease of $\mathrm{pH}$ during the first hour of irradiation in case of higher $\mathrm{c}_{0}$ values led to precipitation of organic contaminants in feed solution. In the time of the reaction a formation of a brownish precipitate was observed, which was found to be soluble under alkaline conditions. The formation and dissolution of this precipitate explains well a significant decrease of TOC amount at the beginning of irradiation and its increase in time of the process (Fig. 3).

Méndez-Arriaga et al. $^{29}$ did not observe formation of any precipitate during photolytic decomposition of DCF under UV-A irradiation. However, the researchers found that the solution changed color from transparent to light-brown. Taking into account that the authors ${ }^{29}$ have applied irradiation within the wavelength range of 290-400 nm, which energy is much weaker than that of UV-C lamp applied in the present studies $\left(\lambda_{\max }=254 \mathrm{~nm}\right)$ the lack of precipitate might be attributed to low concentration of the products forming it. Nonetheless, these by-products must have been present in the solution since it changed color into light-brown ${ }^{29}$. It is also worth noticing that under UV-A irradiation ${ }^{29}$ no mineralization was observed - TOC concentration remained unchanged during $2 \mathrm{~h}$ of experiment.

Agüera et. al. ${ }^{30}$ reported the presence of the red-brown color during the photolysis of DCF under exposure to natural sunlight. They attributed the observed phenomenon to the formation of dimer compounds which are distinguished by the presence of acidic groups and the absence of chlorine atoms. Dimerization may be activated because of the phenol structure from the high mass photoproducts. It was also reported that many of the photoproducts were stable and TOC concentration remained constant ${ }^{30}$.

Analysis of the results discussed above leads to the conclusion that photolysis in the presence of UV-C radiation contributes significantly to DCF degradation.

The product of the photolysis - DCMD hybrid process is distillate. As it was mentioned earlier, only volatile compounds can pass through the DCMD membrane. Therefore, during membrane distillation of non-volatile compounds, the distillate quality should not depend on the feed composition. The quality of the distillate was evaluated on a basis of DCF, TOC, conductivity, TDS and $\mathrm{pH}$ measurements.

Regardless of the process conditions, diclofenac sodium salt was not detected in distillate since as a non-volatile compound it was not transferred through the membrane. TOC quantities in distillate increased with the increase of the initial concentration of DCF in feed and were in the range from $0.2 \mathrm{mg}$ to $0.5 \mathrm{mg}\left(0.3-1 \mathrm{mg} \mathrm{C} / \mathrm{dm}^{3}\right.$ in permeate) for $0.005-0.15 \mathrm{mmol} \mathrm{DCF} / \mathrm{dm}^{3}$, respectively. The observed phenomenon resulted from higher amounts of volatile by-products formed at higher $\mathrm{c}_{0}$. Conductivity and TDS concentration also increased in time and after 5 hours of irradiation were in range of 1.19-1.56 $\mu \mathrm{S} / \mathrm{cm}$ and 0.74-0.97 ppm; however, no clear dependence of these parameters on $c_{0}$ was observed. The increase of distillate conductivity and TDS concentration was associated with transport of carbon dioxide and volatile by-products of DCF degradation through the membrane.

\section{Effect of $\mathrm{TiO}_{2}$ loading on DCF degradation and distillate quality in the hybrid photocatalysis - DCMD system}

Based on the distillate quality, the hybrid photolysis DCMD process can be regarded as an effective method of treatment of solutions contaminated with DCF. However, photolysis was efficient only in decomposition of DCF, but not in its complete mineralization. Therefore, although the concentrate did not contain DCF, it was still contaminated with organic compounds. To improve the treatment efficiency, in the next stage of the investigations photocatalysis instead of photolysis was coupled with DCMD.

At the beginning of this step of the research the influence of $\mathrm{TiO}_{2}$ loading on the effectiveness of DCF photodegradation was investigated. The initial DCF concentration used in this set of experiments was equal to $0.1 \mathrm{mmol} / \mathrm{dm}^{3}$. No influence of the presence of $\mathrm{TiO}_{2}$ on the permeate flux was observed within the investigated range of the photocatalysts loadings $\left(0.05-0.4 \mathrm{~g} / \mathrm{dm}^{3}\right)$, which is consistent with our previous reports ${ }^{31}$.

The influence of $\mathrm{TiO}_{2}$ loading on DCF photodecomposition rate in feed is shown in Fig. 4. Before the UV lamp was switched on $(\mathrm{t}=0 \mathrm{~min})$ the adsorption in the dark was conducted for $30 \mathrm{~min}$. The highest quantity of DCF ( $28 \%$ of the initial amount) was adsorbed on the photocatalyst when the highest $\mathrm{TiO}_{2}$ loading was used $\left(0.4 \mathrm{~g} \mathrm{TiO}_{2} / \mathrm{dm}^{3}\right)$. At lower $\mathrm{TiO}_{2}$ loadings the concentration of DCF decreased due to adsorption for less than $15 \%$. The results shown in Fig. 4 are inconsistent with the data presented by Méndez-Arriaga et al. ${ }^{29}$, who found that the adsorption of $\mathrm{DCF}$ on $\mathrm{TiO}_{2}$ particles did not cause any significant reduction of the drug concentration during the photocatalytic process. One reason for that could be various temperatures applied $\left(30^{\circ} \mathrm{C}\right.$ in ${ }^{29}$ and $60^{\circ} \mathrm{C}$ in the present research). Martinez et al. ${ }^{9}$ also investigated photocatalytic degradation of diclofenac and reported $5 \%$ adsorption of $\mathrm{DCF}$ on $\mathrm{TiO}_{2} \mathrm{P} 25$. Taking into consideration that the reactions of photocatalytic oxidation take place between the adsorbed substrates and the surface reactive species $\left(\mathrm{h}^{+}, \mathrm{OH} \bullet\right)$ a higher adsorption of DCF on the photocatalyst surface should

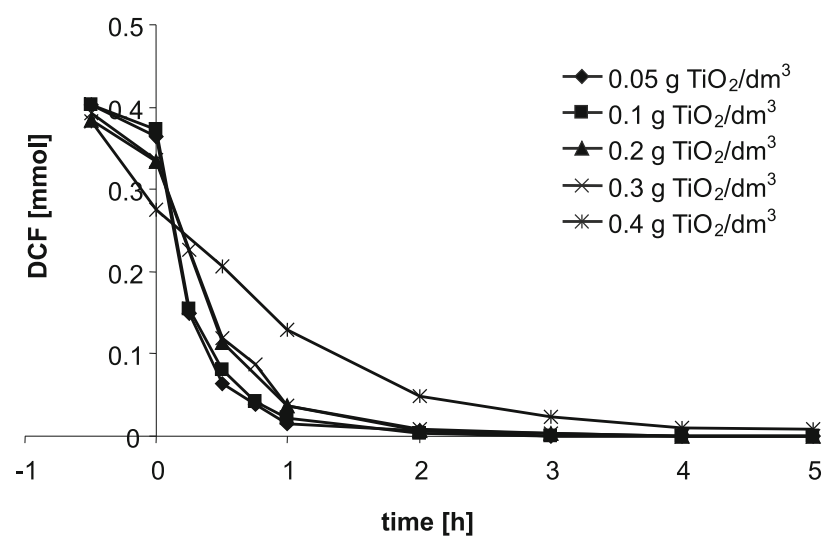

Figure 4. Effect of $\mathrm{TiO}_{2}$ loading on the effectiveness of DCF decomposition in the hybrid photocatalysis - DCMD process. Initial DCF concentration: $0.1 \mathrm{mmol} / \mathrm{dm}^{3}$, $\mathrm{TiO}_{2}$ loading: $0.05-0.4 \mathrm{~g} \mathrm{TiO}_{2} / \mathrm{dm}^{3}$; feed volume: 3.8 $\mathrm{dm}^{3}$; reaction temperature: $60^{\circ} \mathrm{C}$ 
contribute to the improvement of the efficiency of its degradation.

The results shown in Fig. 4 indicate that the effectiveness of DCF photodecomposition depended strongly on $\mathrm{TiO}_{2}$ concentration. In case of the photocatalyst loadings in the range of $0.05-0.3 \mathrm{~g} / \mathrm{dm}^{3}$, a complete DCF removal was reached within the first $3 \mathrm{~h}$. In case of the highest photocatalyst dose equal to $0.4 \mathrm{~g} / \mathrm{dm}^{3}$ the degradation was slower, at the end of the irradiation $98 \%$ of DCF was removed. These results indicate that the latter concentration of $\mathrm{TiO}_{2}$ was too high since the decrease in the DCF degradation rate took place. This might be attributed to the so-called screening effect. At higher photocatalyst loadings, the excess of photocatalyst particles may mask part of the photosensitive surface and consequently hinder light penetration which leads to a decrease of the photodegradation efficiency. This limiting loading depends on the reactor geometry and operating conditions ${ }^{32}$.

On a basis of the results shown in Fig. 4 it was concluded that the most favourable $\mathrm{TiO}_{2}$ concentration was $0.1 \mathrm{~g} / \mathrm{dm}^{3}$, in case of which after $2 \mathrm{~h}$ of irradiation almost $99 \%$ of DCF was decomposed. The literature data show that the optimum photocatalyst concentration strongly depends on parameters such as process conditions, reactor geometry or UV light wavelengths. For example, Martinez et al. ${ }^{11}$ performed an experiment during which the most effective $\mathrm{TiO}_{2}$ P25 loading towards the decomposition of DCF under UV-A light was found to be $1.0 \mathrm{~g} / \mathrm{dm}^{3}$. On the opposite, Achilleos et al. $^{33}$ examined decomposition of $10 \mathrm{mg} / \mathrm{dm}^{3} \mathrm{DCF}$ at various $\mathrm{TiO}_{2}$ loadings $\left(0.05-0.8 \mathrm{~g} / \mathrm{dm}^{3}\right)$ and found that the highest level of conversion can be reached with the use of the lowest $\mathrm{TiO}_{2}$ concentration $\left(0.05 \mathrm{~g} / \mathrm{dm}^{3}\right)$. However, regardless of the $\mathrm{TiO}_{2}$ concentration used in the experiment, final degree of DCF decomposition did not reach more than $85 \%$. Taking into consideration, that the researchers ${ }^{\mathbf{3 3}}$ applied a UV-A light source, it can be concluded that UV-C radiation, which was used in the present study strongly contributes to the improvement of the effectiveness of DCF removal.

In Fig. 5 the percentage of TOC removal vs. $\mathrm{TiO}_{2}$ loading is shown. During the first hour of photocatalysis - DCMD process TOC amount decreased from 66.6 to $32.6 \mathrm{mg}$ (48.8\% of TOC removal) in case of $0.4 \mathrm{~g}$ $\mathrm{TiO}_{2} / \mathrm{dm}^{3}$ and from 64.9 to $21.5 \mathrm{mg}(66.9 \%)$ in case of

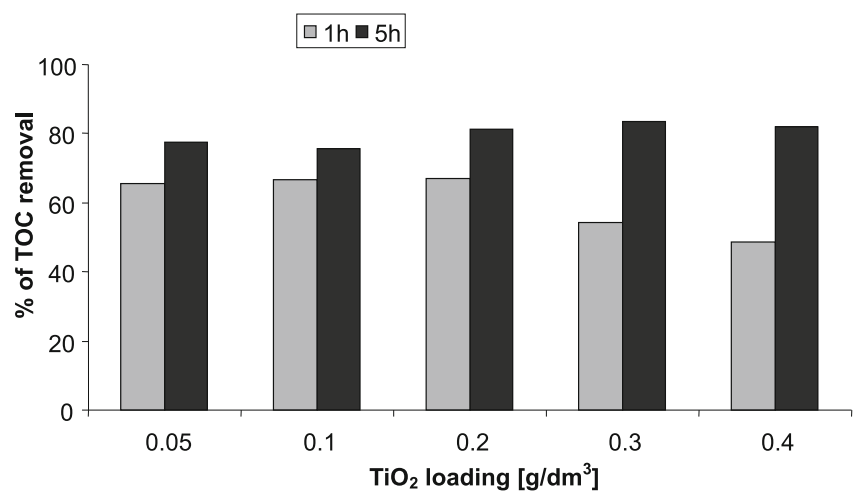

Figure 5. Effect of $\mathrm{TiO}_{2}$ loading on the effectiveness of DCF mineralization in the hybrid photocatalysis - DCMD process. Initial DCF concentration: $0.1 \mathrm{mmol} / \mathrm{dm}^{3}$; $\mathrm{TiO}_{2}$ loading: $0.05-0.4 \mathrm{~g} \mathrm{TiO}_{2} / \mathrm{dm}^{3}$; feed volume: 3.8 $\mathrm{dm}^{3}$; reaction temperature: $60^{\circ} \mathrm{C}$
$0.2 \mathrm{~g} \mathrm{TiO}_{2} / \mathrm{dm}^{3}$. For $\mathrm{TiO}_{2}$ loadings of $0.05-0.2 \mathrm{~g} / \mathrm{dm}^{3}$ no significant influence of the photocatalyst amount on mineralization rate was observed, however, an increase of $\mathrm{TiO}_{2}$ concentration to $0.3 \mathrm{~g} / \mathrm{dm}^{3}$ led to a decrease in the efficiency of TOC removal. When the results after $5 \mathrm{~h}$ of irradiation are considered, the tendency is different. At the end of the process the percentage of TOC removal raised to 75.6-83.5\% and the highest efficiency of mineralization was found in case of $\mathrm{TiO}_{2}$ loading equal to $0.3 \mathrm{~g} \mathrm{TiO}_{2} / \mathrm{dm}^{3}$. The observed variations in the efficiency of mineralization in time could be attributed to changes of $\mathrm{pH}$ and formation of the brown precipitate, which was also observed in case of the photolysis - DCMD process. Within the first hour of irradiation a rapid decrease of $\mathrm{pH}$ from 5.7 to 4.1 for $0.05 \mathrm{~g} \mathrm{TiO}_{2} / \mathrm{dm}^{3}$ was observed. After that time $\mathrm{pH}$ remained constant till the end of the process. However, in case of $0.4 \mathrm{~g} \mathrm{TiO}_{2} / \mathrm{dm}^{3} \mathrm{pH}$ decreased from 5.4 to 4.8 during the first hour and then it was decreasing slowly reaching the value of $\mathrm{pH} 4.3$ after $5 \mathrm{~h}$. In the previously described photolysis experiments $\mathrm{pH}$ dropped rapidly and then increased. In the presence of the photocatalyst $\mathrm{pH}$ did not increase after the first hour of irradiation.

Based on the efficiency of mineralization after $5 \mathrm{~h}$ of irradiation the photocatalyst loading of $0.3 \mathrm{~g} \mathrm{TiO}_{2} / \mathrm{dm}^{3}$ was selected for further studies.

Similarly as in case of the hybrid photolysis - DCMD system, the quality of distillate was also monitored in the discussed experiments. The amount of TOC increased with the increase of $\mathrm{TiO}_{2}$ loading and was in the range of $0.5 \mathrm{mg}\left(1.0 \mathrm{mg} / \mathrm{dm}^{3}\right.$ in permeate $)$ to $0.7 \mathrm{mg}\left(1.8 \mathrm{mg} / \mathrm{dm}^{3}\right.$ in permeate) for $0.05-0.4 \mathrm{~g} \mathrm{TiO}_{2} / \mathrm{dm}^{3}$. The results indicate that with the increase of $\mathrm{TiO}_{2}$ loading higher amount of volatile products of DCF degradation must have been formed and passed through the membrane. DCF was not detected in distillate, regardless of process conditions. Conductivity and TDS concentration were increasing in time but no clear dependence of these parameters on $\mathrm{TiO}_{2}$ loading was found. In general, their values did not exceed $1.3 \mu \mathrm{S} / \mathrm{cm}$ and $0.8 \mathrm{ppm}$, respectively. $\mathrm{pH}$ was slightly decreasing in time and after $5 \mathrm{~h}$ of the process performance ranged from $\mathrm{pH} 5.7$ to 5.3.

\section{Effect of the initial concentration of DCF on its removal in the hybrid photocatalysis - DCMD system}

During the next stage of this research the influence of the initial DCF concentration on its removal during the hybrid photocatalysis - DCMD process was evaluated. The $\mathrm{TiO}_{2}$ loading of $0.3 \mathrm{~g} \mathrm{TiO}_{2} / \mathrm{dm}^{3}$ was used. Figure 6 presents changes of the quantity of diclofenac sodium salt in feed. Similarly as in the previously described set of experiments, adsorption in the dark was conducted for $30 \mathrm{~min}$. A noticeable decrease of DCF amount was observed during this stage of the process. On a basis of the results an adsorption isotherm was plotted (Fig. 7). The experimental data were well described by the Freundlich model ${ }^{34}$ :

$\mathrm{q}_{\mathrm{e}}=\mathrm{K}_{\mathrm{F}} \times \mathrm{C}_{\mathrm{e}}^{1 / \mathrm{n}}$

$\log \left(\mathrm{q}_{\mathrm{e}}\right)=\log \left(\mathrm{K}_{\mathrm{F}}\right)+1 / \mathrm{n} \log \left(\mathrm{C}_{\mathrm{e}}\right)$

where $\mathrm{q}_{\mathrm{e}}$ is the amount of DCF in $\mathrm{mg}$ adsorbed per gram of photocatalyst, (mg/g); $\mathrm{K}_{\mathrm{F}}$ is Freundlich isotherm constant $(\mathrm{mg} / \mathrm{g})\left(\mathrm{dm}^{3} / \mathrm{g}\right)^{\mathrm{n}}$ related to adsorption capacity; $\mathrm{C}_{\mathrm{e}}$ is the equilibrium concentration of DCF, $\left(\mathrm{mg} / \mathrm{dm}^{3}\right)$ and 


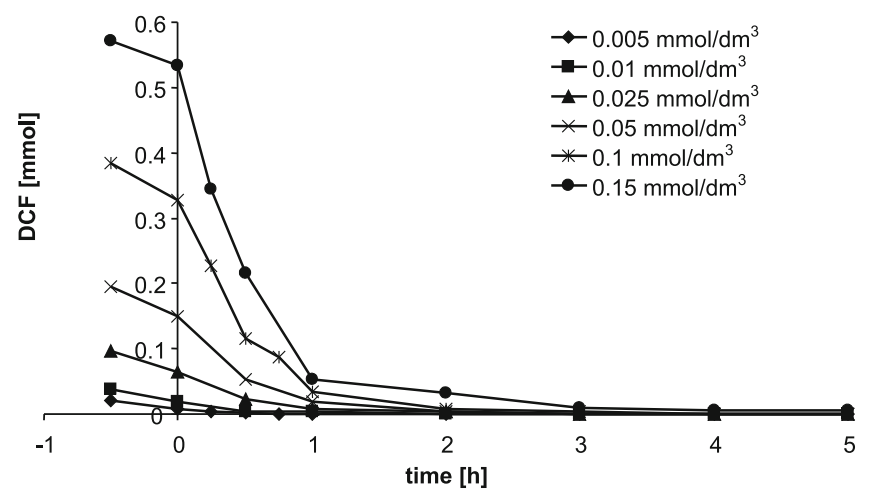

Figure 6. Effect of initial DCF concentration on the effectiveness of its decomposition in the hybrid photocatalysis - DCMD process. $\mathrm{TiO}_{2}$ loading: $0.3 \mathrm{~g} \mathrm{TiO} / \mathrm{dm}^{3}$; initial DCF concentration: $0.005-0.15 \mathrm{mmol} / \mathrm{dm}^{3}$; feed volume: $3.8 \mathrm{dm}^{3}$; reaction temperature $60^{\circ} \mathrm{C}$

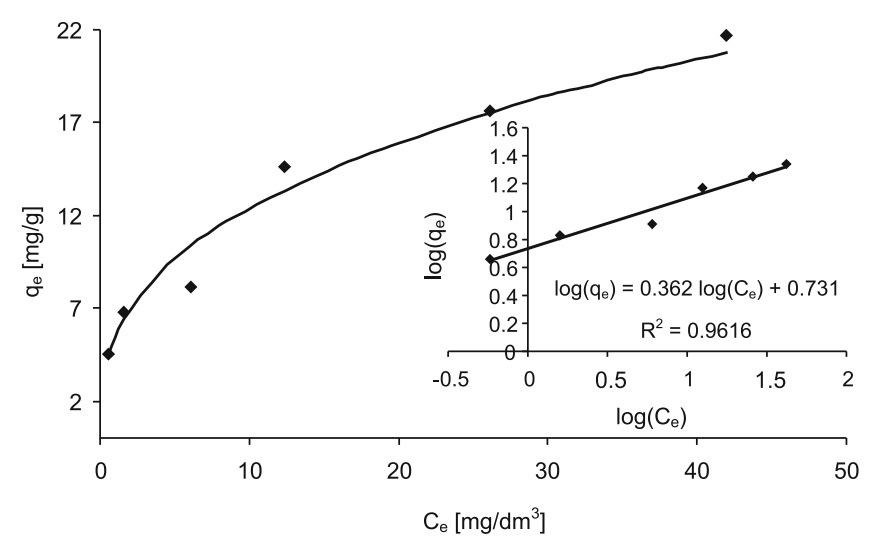

Figure 7. Adsorption isotherm of $\mathrm{DCF}$ on $\mathrm{TiO}_{2} \mathrm{P} 25$ in the photocatalysis - DCMD system. DCF concentration: 0.005-0.15 mmol $/ \mathrm{dm}^{3}, \mathrm{TiO}_{2}$ loading: $0.3 \mathrm{~g} \mathrm{TiO}_{2} / \mathrm{dm}^{3}$, temperature: $60^{\circ} \mathrm{C}$

$\mathrm{n}$ is a dimensionless parameter related to the adsorption intensity. The constants $\mathrm{K}_{\mathrm{F}}$ and $1 / \mathrm{n}$ determined from the intercept and slope of the plot of $\log \left(\mathrm{q}_{\mathrm{e}}\right)$ vs. $\log \left(\mathrm{C}_{\mathrm{e}}\right)$ were equal to 5.38 and 0.362 , respectively.

After adsorption in the dark the UV lamp was switched on $(t=0$, Fig. 6$)$ and the hybrid photocatalysis - DCMD process was started. The time necessary for complete DCF decomposition was the shortest when the lowest initial DCF concentration was used. In case of 0.005 $\mathrm{mmol} / \mathrm{dm}^{3}$ there was no DCF in the feed after $45 \mathrm{~min}$. of irradiation. In case of the highest DCF concentration $\left(0.15 \mathrm{mmol} / \mathrm{dm}^{3}\right)$ the removal of the compound after $5 \mathrm{~h}$ of irradiation was $99.1 \%$. It should be stressed here that although the percentage of the removal was higher in case of $\mathrm{c}_{0}=0.005 \mathrm{mmol} / \mathrm{dm}^{3}$ compared to $\mathrm{c}_{0}=0.15$ $\mathrm{mmol} / \mathrm{dm}^{3}$, the total mass of decomposed DCF was higher in case of the higher drug concentration.

Comparing changes of DCF concentration in feed during the photolysis-DCMD (Fig. 2) and photocatalysis-DCMD (Fig. 6) hybrid processes it can be found that the former was more effective towards the removal of DCF. As was already discussed, in the absence of a photocatalyst DCF was completely decomposed within less than 4 hours of irradiation, regardless of the initial concentration.

Figure 8 presents the effectiveness of mineralization in the feed with reference to the initial DCF concentration. Within the first hour of the process $56 \%$ of
TOC was removed in case of the sample with initial DCF concentration of $0.1 \mathrm{mmol} / \mathrm{dm}^{3}$ and $97 \%$ in case of the sample with $\mathrm{c}_{0}$ of $0.01 \mathrm{mmol} / \mathrm{dm}^{3}$. At the end of the process mineralization was complete in case of the lowest initial DCF concentrations $(0.005-0.025 \mathrm{mmol} /$ $\left.\mathrm{dm}^{3}\right)$. When higher initial amounts of DCF were used $\left(0.05-0.15 \mathrm{mmol} / \mathrm{dm}^{3}\right)$, mineralization reached $82.5-85 \%$.

If the changes of TOC concentration in feed during the photocatalysis - DCMD and photolysis - DCMD processes are compared, it can be observed that the addition of the photocatalyst strongly improved the effectiveness of mineralization. In the photolysis - DCMD process, even in case of the lowest initial concentrations of DCF, the organic compounds were not removed completely, while under the same conditions in photocatalysis - DCMD process a total mineralization was achieved.

Similarly as in the experiments discussed earlier, $\mathrm{pH}$ of the feed was also lowered. With the use of higher initial concentrations of DCF, $\mathrm{pH}$ decreased rapidly in the first 2 hours and after that stabilized $(\mathrm{pH} 3.8$ for $0.15 \mathrm{mmol} \mathrm{DCF} / \mathrm{dm}^{3}$ ). However, in case of lower drug concentrations, $\mathrm{pH}$ decreased, and then increased. For example, for initial DCF concentration of $0.005 \mathrm{mmol} / \mathrm{dm}^{3}$ the initial $\mathrm{pH}$ was 5.7 , after $2 \mathrm{~h}$ it decreased to 5.1 and then increased to $\mathrm{pH} 5.6$ at the end of the process. This means that with the disappearance of all organic compounds the $\mathrm{pH}$ of the feed reached the value similar to the $\mathrm{pH}$ of the ultrapure water, which was applied for preparation of the solutions.

The amount of TOC in distillate depended on the initial DCF concentration and was in the range of $0.2-0.8 \mathrm{mg}$ $\left(0.6-1.9 \mathrm{mg} / \mathrm{dm}^{3}\right.$ in permeate) for $0.005-0.15 \mathrm{mmol} / \mathrm{dm}^{3}$. No DCF was detected in the distillate. Conductivity did not exceed $1.6 \mu \mathrm{S} / \mathrm{cm}$. In case of the lowest initial DCF concentrations $\mathrm{pH}$ decreased slightly from $\mathrm{pH} 5.5$ to 5.3 , whereas in case of the $\mathrm{c}_{0}=0.15 \mathrm{mmol} / \mathrm{dm}^{3} \mathrm{pH}$ decreased to 5.0 .

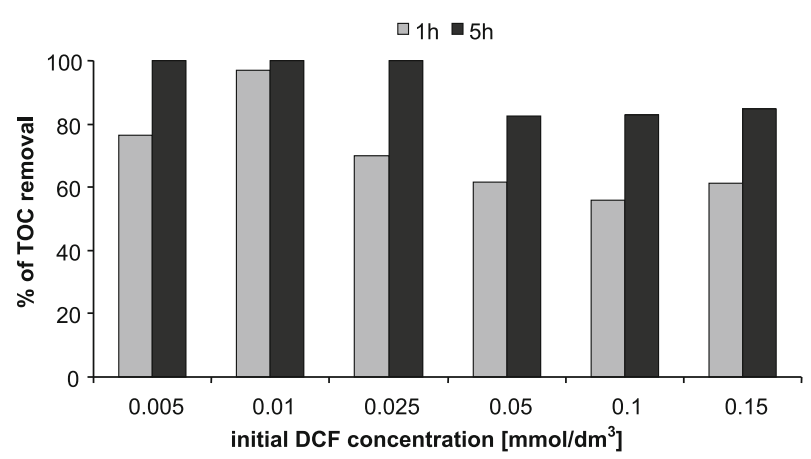

Figure 8. Effect of initial DCF concentration on the effectiveness of its mineralization in the hybrid photocatalysis - DCMD process. $\mathrm{TiO}_{2}$ loading: $0.3 \mathrm{~g} \mathrm{TiO}_{2} / \mathrm{dm}^{3}$; initial DCF concentration: $0.005-0.15 \mathrm{mmol} / \mathrm{dm}^{3}$; feed volume: $3.8 \mathrm{dm}^{3}$; reaction temperature: $60^{\circ} \mathrm{C}$

\section{Comparison of the photolysis - DCMD and photocata- lysis - DCMD hybrid systems}

Figure 9 shows a comparison of changes of DCF and TOC amount in feed solution during DCMD alone and in photolysis - DCMD and photocatalysis - DCMD processes. The initial concentration of the model compound was $0.1 \mathrm{mmol} / \mathrm{dm}^{3}$. During DCMD the amount of DCF in the feed was constant, which indicates that 

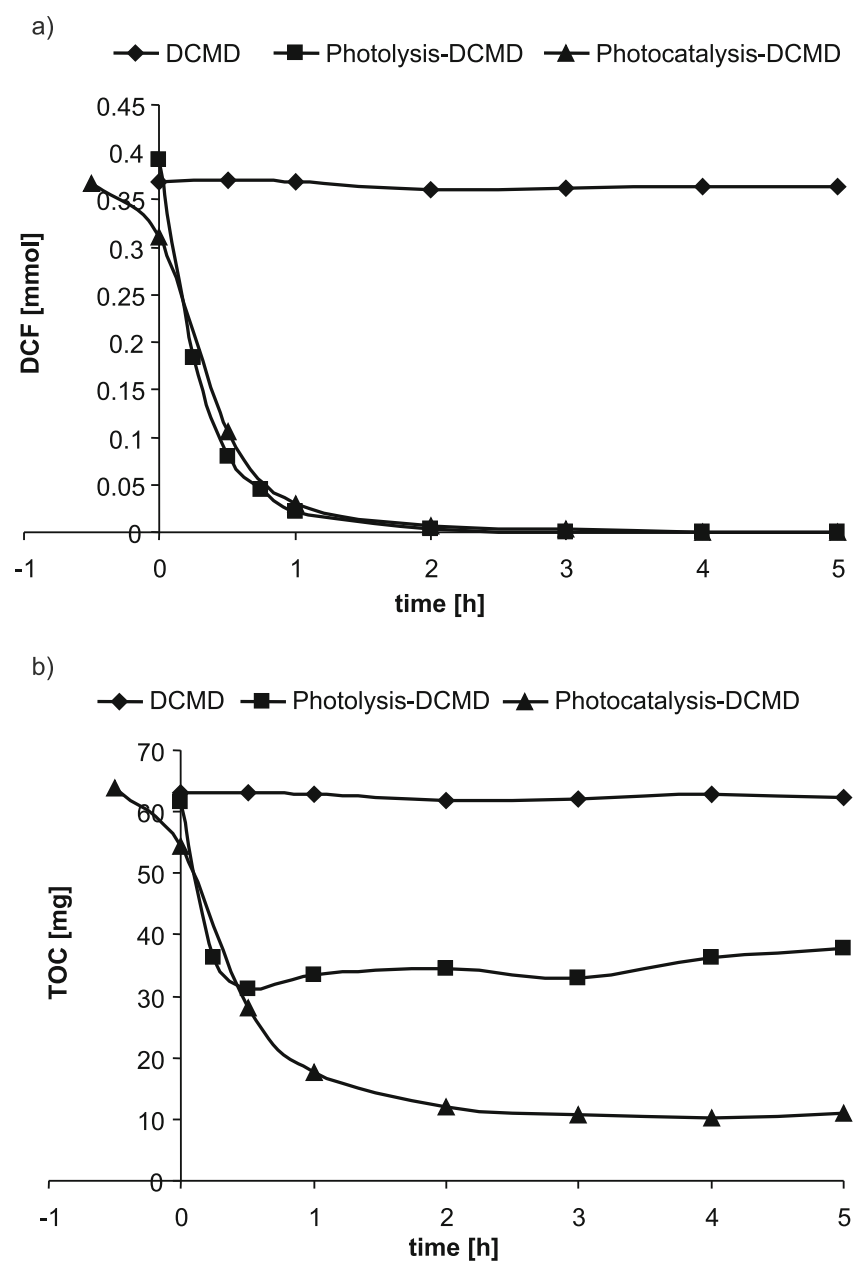

Figure 9. Comparison of DCMD, photolysis - DCMD and photocatalysis - DCMD processes applied for removal of DCF from water. Initial DCF concentration: $0.1 \mathrm{mmol} / \mathrm{dm}^{3} ; \mathrm{TiO}_{2}$ loading (photocatalysis - DCMD): $0.3 \mathrm{~g} / \mathrm{dm}^{3}$; feed volume: $3.8 \mathrm{dm}^{3}$; reaction temperature/feed temperature in the feed tank: $60^{\circ} \mathrm{C}$

$\mathrm{C}_{14} \mathrm{H}_{10} \mathrm{Cl}_{2} \mathrm{NNaO}_{2}$ was not transported through the membrane. Moreover, the data show that under heating (feed temperature of $60^{\circ} \mathrm{C}$ ) the model drug did not undergo degradation.

When decomposition of DCF is considered, the photolysis process was found to be slightly more effective than photocatalysis. In case of the photolysis, a complete decomposition of the model compound took place in less than 3 hours, whereas in case of the photocatalysis, DCF was decomposed within 4 hours. However, if we consider the mineralization, photocatalysis was significantly more efficient. Without the use of the photocatalyst, TOC amount after 5 hours of irradiation was equal to $37.7 \mathrm{mg}$ (39.8\% of TOC removal), and in the presence of $0.3 \mathrm{~g}$ $\mathrm{TiO}_{2} / \mathrm{dm}^{3}$ TOC amount after $5 \mathrm{~h}$ was equal to $11 \mathrm{mg}$ (82.7\% of TOC removal).

The enhancement of TOC removal with the use of the photocatalyst can be ascribed to the photogeneration of hydroxyl radicals, which are strong oxidizing species. The oxidation of DCF can lead to the cleavage of aromatic rings into organic acids and subsequently to the formation of $\mathrm{CO}_{2}, \mathrm{H}_{2} \mathrm{O}$ and other inorganic compounds ${ }^{29}$.

According to Lekkerkerker-Teunissen et al. ${ }^{35}$ the degradation pathway of DCF in the photolysis process proceeds first through dechlorination and a ring closure forming chlorocarbazole acetic acid, which can either undergo dechlorination/hydroxylation or decarboxylation ending in a quinone-like transformation product. Agüera et al. ${ }^{30}$ proposed a reaction pathway in which DCF undergoes decarboxylation and a ring closure, but the degradation products can also form dimers.

The reaction pathway of the degradation of DCF in the photocatalysis process was proposed by Calza et al. ${ }^{36}$. During the process, DCF can lose water molecule, formic acid or chlorine radical. Some of the products can be formed through an $\mathrm{OH} \bullet$ attack leading to the hydroxylation of the molecule, and subsequently, fragmentation of these products leading to formation of compounds with one aromatic ring.

During the first hour of the photolysis-DCMD and photocatalysis-DCMD the changes of DCF concentration in feed were similar. This was because DCF was undergoing a photolytic degradation. The most visible difference between photolysis and photocatalysis can be observed in final stages of DCF degradation during which products which do not undergo direct photolysis in the presence of the used irradiation are formed. In this case, in photolysis-DCMD process, TOC amount reached a plateau. On the opposite, with the use of the photocatalyst, the degradation can proceed further and due to the presence of surface reactive species $\left(\mathrm{HO} \bullet, \mathrm{h}^{+}\right)$ the total mineralization of the organic compounds is possible to be obtained ${ }^{36}$.

In photolysis - DCMD as well as in photocatalysis DCMD systems $\mathrm{pH}$ of the feed decreased to about 4 . These results indicate the formation of the products with the acidic properties. The main compound responsible for such a decrease of $\mathrm{pH}$ is $\mathrm{HCl}$ generated via dechlorination of DCF and its by-products ${ }^{30}$. The presence of $\mathrm{HCl}$ was also responsible for very low concentration of inorganic carbon in feed solution $\left(<0.3 \mathrm{mg} / \mathrm{dm}^{3}\right)$. This was beneficial from the photocatalytic point of view, since the well known hydroxyl radical scavengers, which are carbonates and bicarbonates, were eliminated from the treated solution. Nonetheless, the contribution of organic acids formed during DCF degradation to the changes of solution $\mathrm{pH}$ should be also considered ${ }^{23}$. On a basis of HPLC analysis of the feed solutions the presence of formic, oxalic and malic acids in case of the photolysis - DCMD process and formic, succinic and malic acids in case of the photocatalysis - DCMD was observed.

Figure 10 shows that the initial rates $\left(r_{0}\right)$ of diclofenac sodium salt decomposition in both hybrid processes were increasing with increasing initial amount of the model compound and that the dependency was linear. For the photolysis - DCMD hybrid process the $\mathrm{r}_{0}$ values ranged from $0.00053 \mathrm{mmol} / \mathrm{min}(0.17 \mathrm{mg} / \mathrm{min})$ for $\mathrm{c}_{0}=0.005$ $\mathrm{mmol} / \mathrm{dm}^{3}$ to $0.014 \mathrm{mmol} / \mathrm{min}(4.47 \mathrm{mg} / \mathrm{min})$ for $\mathrm{c}_{0}=0.15$ $\mathrm{mmol} / \mathrm{dm}^{3}$, whereas in case of the photocatalysis - DCMD system the initial decomposition rates were lower and ranged from $0.00015 \mathrm{mmol} / \mathrm{min}(0.047 \mathrm{mg} / \mathrm{min})$ for $\mathrm{c}_{0}=0.005 \mathrm{mmol} / \mathrm{dm}^{3}$ to $0.008 \mathrm{mmol} / \mathrm{min}(3.72 \mathrm{mg} / \mathrm{min})$ for $\mathrm{c}_{0}=0.15 \mathrm{mmol} / \mathrm{dm}^{3}$. Similar dependency was observed in case of TOC degradation. For the photolysis - DCMD system the initial rates of mineralization ranged from $0.026 \mathrm{mg} / \mathrm{min}$ for $\mathrm{c}_{0}=0.005 \mathrm{mmol} / \mathrm{dm}^{3}$ (initial TOC mass equal to $2.93 \mathrm{mg}$ ) to $1.42 \mathrm{mg} / \mathrm{min}$ for $\mathrm{c}_{0}=0.15$ $\mathrm{mmol} / \mathrm{dm}^{3}$ (initial TOC mass equal to $96.1 \mathrm{mg}$ ); while for the photocatalysis - DCMD system the $r_{0}$ values ranged 
a)

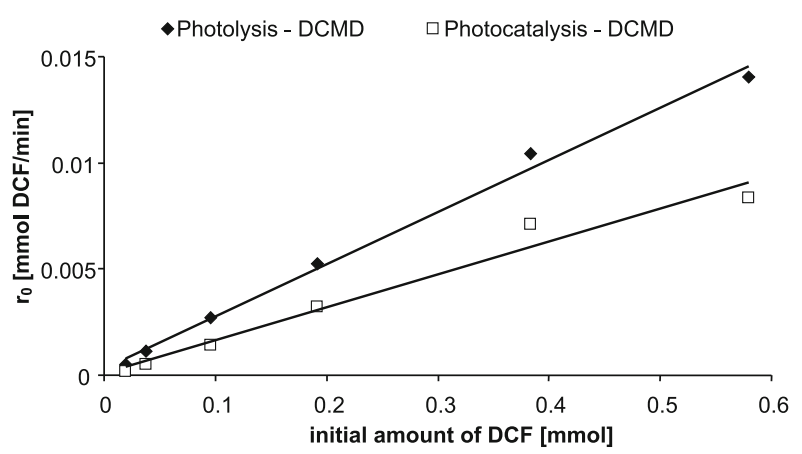

b)

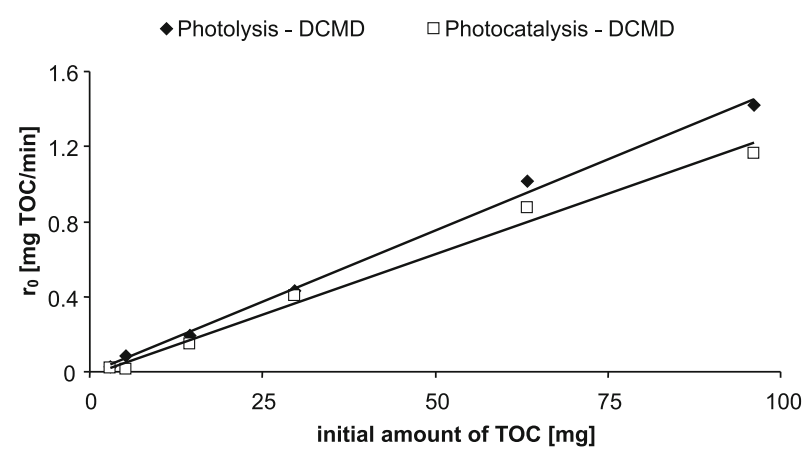

Figure 10. The effect of initial amount of DCF and TOC on initial rate of DCF decomposition and mineralization in photolysis - DCMD and photocatalysis - DCMD processes

from $0.02 \mathrm{mg} / \mathrm{min}$ for $\mathrm{c}_{0}=0.005 \mathrm{mmol} / \mathrm{dm}^{3}$ (initial TOC mass equal to $2.93 \mathrm{mg}$ ) to $1.16 \mathrm{mg} / \mathrm{min}$ for $\mathrm{c}_{0}=0.15$ $\mathrm{mmol} / \mathrm{dm}^{3}$ (initial TOC mass equal to $96.1 \mathrm{mg}$ ).

If the initial degradation rates are compared, it can be concluded that the photolysis - DCMD hybrid process is more effective towards the removal of DCF from water. But these parameters reflect only the very beginning stage of the decomposition and within the next hours the degradation rate was slowing down. This is especially observable when mineralization is considered (Figs. 3 and 5). From this point of view the photocatalysis - DCMD system exhibits much better performance. The main goal of the present research was to purify the water from both DCF and the by-products of its decomposition, not only from the model drug, therefore it is more important to know the final result of the process, which is the quantity of the compounds left in the reaction mixture, rather than the initial degradation rate.

Although the efficiency of DCF degradation in feed solution is important, it must be, however, remembered that the main product of the photolysis - DCMD and photocatalysis - DCMD hybrid processes is distillate. As was explained earlier, diclofenac sodium salt is a non-volatile compound, therefore it was not transported through the DCMD membrane and, thus, not detected in the distillate.

Table 1 presents a comparison of TOC amounts in distillate (permeate) at the end of various experiments with the initial and final amounts of organic carbon in feed solutions. In the photolysis - DCMD system the amount of TOC in the distillate was $0.5 \mathrm{mg}\left(1.2 \mathrm{mg} / \mathrm{dm}^{3}\right.$ in permeate) whereas in the photocatalysis - DCMD system it was equal to $0.7 \mathrm{mg}\left(1.8 \mathrm{mg} / \mathrm{dm}^{3}\right.$ in permeate). These results may indicate that with the use of the photocatalyst the photodegradation was deeper and more of the volatile compounds, such as carboxylic acids, were formed and then transported through the DCMD membrane. Nonetheless, the total effectiveness of TOC removal in both hybrid systems was very high and ranged from 98.9 to $99.2 \%$.

Analysis of conductivity and TDS concentration in distillate revealed that both parameters were slowly increasing in time. At the end of the DCMD conducted alone they reached $1.22 \mu \mathrm{S} / \mathrm{cm}$ and $0.76 \mathrm{ppm}$, respectively. In case of photolysis - DCMD and photocatalysis - DCMD processes they were in the range of $1.26-1.6 \mu \mathrm{S} / \mathrm{cm}$ and $0.78-1.11 \mathrm{ppm}$, respectively. It is also worth noting that the distillate quality was comparable to the quality of pure water used for preparation of solutions, which

Table 1. Comparison of TOC amounts in distillate (permeate) after $5 \mathrm{~h}$ of DCMD, photolysis-DCMD and photocatalysis-DCMD processes with the initial and final TOC amounts in feed solutions. Initial DCF concentration: $0.1 \mathrm{mmol} / \mathrm{dm}^{3} ; \mathrm{TiO}_{2}$ loading (photocatalysis - DCMD): $0.3 \mathrm{~g} / \mathrm{dm}^{3}$; feed volume: $3.8 \mathrm{dm}^{3}$; reaction temperature/ feed temperature in the feed tank: $60^{\circ} \mathrm{C}$

\begin{tabular}{|l|c|c|c|}
\hline & DCMD & $\begin{array}{c}\text { Photolysis - } \\
\text { - DCMD }\end{array}$ & $\begin{array}{c}\text { Photocatalysis - } \\
\text { - DCMD }\end{array}$ \\
\hline $\begin{array}{l}\text { TOC in feed after } \\
0 \mathrm{~h} \text { [mg] }\end{array}$ & 64.2 & 62.7 & 64.0 \\
\hline $\begin{array}{l}\text { TOC in feed after } \\
5 \mathrm{~h} \text { [mg] }\end{array}$ & 64.0 & 37.7 & 11.0 \\
\hline $\begin{array}{l}\text { TOC in distillate } \\
\text { after 5 } \mathrm{h} \text { [mg] }\end{array}$ & 0 & 0.5 & 0.7 \\
\hline
\end{tabular}

conductivity and TDS concentration were equal to 0.9 $\mu \mathrm{S} / \mathrm{cm}$ and $0.53 \mathrm{ppm}$, respectively.

\section{CONCLUSIONS}

The presented results indicate that both of the examined hybrid processes, i.e. photolysis - DCMD and photocatalysis - DCMD can be applied for removal of NSAIDs, such as DCF, from water. A complete decomposition of $\mathrm{C}_{14} \mathrm{H}_{10} \mathrm{Cl}_{2} \mathrm{NNaO}_{2}$ in a feed was obtained in both processes. The effectiveness of TOC mineralization in case of the photolysis - DCMD system was in the range of $27.3-48.7 \%$, depending on the initial concentration of DCF. The addition of the photocatalyst significantly improved the effectiveness of TOC degradation. After $5 \mathrm{~h}$ of the hybrid photocatalysis-DCMD process the mineralization efficiency was in the range of $82.5-100 \%$, being the highest for the lowest DCF concentration. The effectiveness of TOC degradation was also influenced by the photocatalyst loading. The highest degree of mineralization was obtained when $0.3 \mathrm{~g} \mathrm{TiO}_{2} / \mathrm{dm}^{3}$ was used.

Application of DCMD in the hybrid systems ensured high efficiency of separation of DCF as well as products of its degradation. Therefore, the type of the process used for the removal of DCF from water (DCMD, photolysis-DCMD, photocatalysis-DCMD) did not have much influence on the quality of the main product (distillate). Regardless of the process applied, distillate was a high purity water free of diclofenac sodium salt. Moreover, TOC amount did not exceed the value of $0.8 \mathrm{mg}$ and conductivity was lower than $1.6 \mu \mathrm{S} / \mathrm{cm}$. 
An important issue is that in case of the hybrid systems DCF was removed also from the feed solution, which could be regarded as a solution of the problem of contaminated concentrate, occurring when DCMD is conducted alone.

\section{LITERATURE CITED}

1. Ternes, T.A. (1998). Occurence of drugs in German sewage treatment plants and rivers. Water Res. 32 (11) 3245-3260. DOI: 10.1016/S0043-1354(98)00099-2.

2. Halling-Sørensen, B., Nors Nielsen, S., Lanzky, P.F., Ingerslev, F., Holten Lützhøft, H.C. \& Jørgensen, S.E. (1998). Occurrence, fate and effects of pharmaceutical substances in the environment - a review. Chemosphere. 36 (2) 357-393. DOI: 10.1016/S0045-6535(97)00354-8.

3. Coelho, A.D., Sans, C., Agüera, A., Gómez, M.J., Esplugas, S., \& Dezotti, M. (2009). Effects of ozone pre-treatment on diclofenac: Intermediates, biodegradability and toxicity assessment. Sci. Total Environ. 407, 3572-3578. DOI: 10.1016/j. scitotenv.2009.01.013.

4. Rizzo, L., Meric, S., Kassinos, D., Guida, M., Russo, F. \& Belgiorno, V. (2009). Degradation of diclofenac by $\mathrm{TiO}_{2}$ photocatalysis: UV absorbance kinetics and process evaluation through a set of toxicity bioassays. Water Res. 43, 979-988. DOI: 10.1016/j.watres.2008.11.040.

5. Musa, K.A. \& Eriksson, L.A. (2009). Photodegradation mechanism of the common non-steroid anti-inflammatory drug diclofenac and its carbazole photoproduct. Phys. Chem. Chem. Phys. 11, 4601-4610. DOI: 10.1039/B900144A.

6. Czech, B. \& Ćwikła-Bundyra, W. (2007). Band reactor for toxic and recalcitrant water contaminants. Pol. J. Chem. Technol. 9 (4) 18-20. DOI: 10.2478/v10026-007-0082-z.

7. Garcia-Araya, J.F., Beltran, F.J. \& Aguinaco, A. (2010). Diclofenac removal from water by ozone and photolytic $\mathrm{TiO}_{2}$ catalysed processes. J. Chem. Technol. Biotechnol. 85, 798-804. DOI: $10.1002 /$ jctb.2363.

8. Madhavan, J., Kumar, P.S.S., Anandan, S., Zhou, M., Grieser, F., \& Ashokkumar, M. (2010). Ultrasound assisted photocatalytic degradation of diclofenac in an aqueous environment. Chemosphere. 80, 747-752. DOI: 10.1016/j.chemosphere.2010.05.018.

9. Ravina, M., Campanella, L. \& Kiwi, J. (2002). Accelerated mineralization of the drug Diclofenac via Fenton reactions in a concentric photo-reactor. Water Res. 36, 3553-3560. DOI: 10.1016/S0043-1354(02)00075-1.

10. Rivas, J., Gimeno, O., Borralho, T. \& Beltrán, F. (2010). Influence of oxygen and free radicals promoters on the UV-254 nm photolysis of diclofenac. Chem. Eng. J. 163, 35-40. DOI: 10.1016/j.cej.2010.07.027.

11. Martínez, C., Canle L.M., Fernández, M.I., Santaballa, J.A. \& Faria J. (2011). Aqueous degradation of diclofenac by heterogeneous photocatalysis using nanostructured materials. Appl. Catal. B-Environ. 107, 110-118. DOI: 10.1016/j. apcatb.2011.07.003.

12. Mozia, S. (2010). Photocatalytic membrane reactors (PMRs) in water and wastewater treatment. A review. Sep. Purif. Technol. 73, 71-91. DOI: 10.1016/j.seppur.2010.03.021.

13. Ryu, J., Choi, W. \& Choo, K.H. (2005). A pilot-scale photocatalyst-membrane hybrid reactor: performance and characterization. Water Sci. Technol. 51, 491-497.

14. Shon, H.K., Phuntsho, S. \& Vigneswaran, S. (2008). Effect of photocatalysis on the membrane hybrid system for wastewater treatment. Desalination. 225, 235-248. DOI: 10.1016/j.desal.2007.05.032.

15. Sun, X., Zhang, J., Zhang, G., Pan, X. \& Huang, T. (2012). Preparation and characteristics of $\mathrm{TiO}_{2}$ nanotube catalysts used in hybrid photocatalysis/membrane process. Catal. Commun. 18, 76-80. DOI: 10.1016/j.catcom.2011.11.026.
16. Sarasidis, V.C., Patsios, S.I. \& Karabelas. A.J. (2011). A hybrid photocatalysis-ultrafiltration continuous process: The case of polysaccharide degradation. Sep. Purif. Technol. 80, 73-80. DOI: 10.1016/j.seppur.2011.04.010.

17. Grzechulska-Damszel, J., Mozia, S. \& Morawski, A.W. (2010). Integration of photocatalysis with membrane processes for purification of water contaminated with organic dyes. Catal. Today. 156 (3-4), 295-300. DOI: 10.1016/j.cattod.2010.06.033.

18. Grzechulska-Damszel, J. \& Morawski, A.W. (2007). Removal of organic dye in the hybrid photocatalysis/membrane processes system. Pol. J. Chem. Technol. 9 (2) 94-98. DOI: 10.2478/v10026-007-0036-5.

19. Molinari, R., Pirillo, F., Falco, M., Loddo, V. \& Palmisano, L. (2004). Photocatalytic degradation of dyes by using a membrane reactor. Chem. Eng. Process. 43 (9) 1103-1114. DOI: 10.1016/j.cep.2004.01.008.

20. Azrague, K., Aimar, P., Benoit-Marquie, F. \& Maurette, M.T. (2007). A new combination of a membrane and a photocatalytic reactor for the depollution of turbid water. Appl. Catal. B-Environ. 72 (3-4) 197-204. DOI: 10.1016/j. apcatb.2006.10.007.

21. Camera-Roda, G., Santarelli, F., Augugliaro, V., Loddo, V., Palmisano, G., Palmisano, L. \& Yurdakal, S. (2011). Photocatalytic process intensification by coupling with pervaporation. Catal. Today. 161, 209-213. DOI: 10.1016/j.cattod.2010.10.052.

22. Mozia, S., Tomaszewska, M. \& Morawski, A.W. (2007). Photocatalytic membrane reactor (PMR) coupling photocatalysis and membrane distillation - Effectiveness of removal of three azo dyes from water. Catal. Today. 129, 3-8. DOI: 10.1016/j.cattod.2007.06.043.

23. Mozia, S. (2010). Application of temperature modified titanate nanotubes for removal of an azo dye from water in a hybrid photocatalysis-MD process. Catal. Today. 156, 198-207. DOI: $10.1016 /$ j.cattod.2010.02.026.

24. Mozia, S., Tsumura, T., Toyoda, M. \& Morawski, A.W. (2011). Degradation of ibuprofen sodium salt in a hybrid photolysis - membrane distillation system utilizing germicidal UVC lamp. J. Adv. Oxid. Technol. 14 (1) 31-39. DOI: 10.1016/j. cattod.2012.03.016.

25. Mozia, S., Morawski, A.W. \& Toyoda, M. (2012). The influence of solution composition on the effectiveness of degradation of ibuprofen sodium salt in a hybrid photocatalysis - membrane distillation system. J. Adv. Oxid. Technol. 15 (1) 21-29.

26. Mozia, S. \& Morawski, A.W. (2012). The performance of a hybrid photocatalysis-MD system for the treatment of tap water contaminated with ibuprofen. Catal. Today. 193, 213-220. DOI: 10.1016/j.cattod.2012.03.016.

27. Braslavsky, S.E., Braun, A.M., Cassano, A.E., Emeline, A.V., Litter, M.I., Palmisano, L., Parmon, V.N. \& Serpone, N. (2011). Glossary of terms used in photocatalysis and radiation catalysis (IUPAC Recommendations 2011). Pure Appl. Chem. 83 (4) 931-1014. DOI: 10.1351/PAC-REC-09-09-36.

28. Kim, I. \& Tanaka, H. (2009). Photodegradation characteristics of PPCPs in water with UV treatment. Environ. Int. 35 (5) 793-802. DOI: 10.1016/j.envint.2009.01.00.

29. Méndez-Arriaga, F., Esplugas, S. \& Giménez, J. (2008). Photocatalytic degradation of non-steroidal anti-inflammatory drugs with $\mathrm{TiO}_{2}$ and simulated solar irradiation. Water Res. 42, 585-594. DOI: 10.1016/j.watres.2007.08.002.

30. Agüera, A., Pérez Estrada, L.A., Ferrer, I., Thurman, E.M., Malato, S., \& Fernández-Alba, A.R. (2005). Application of time-of-flight mass spectrometry to the analysis of phototransformation products of diclofenac in water under natural sunlight. J. Mass Spectrom. 40 (7) 908-915. DOI: 10.1002/ jms.867.

31. Mozia, S. \& Morawski, A.W. (2006). Hybridization of photocatalysis and membrane distillation for purification of wastewater. Catal. Today 118, 181-188. DOI: 10.1016/j.cattod.2005.12.003. 
32. Herrmann, J.M. (2005). Heterogeneous photocatalysis state of the art and present applications. Top. Catal. 34 (1-4) 49-65. DOI: 10.1007/s11244-005-3788-2.

33. Achilleos, A., Hapeshi, E., Xekoukoulotakis, N.P., Mantzavinos, D. \& Fatta-Kassinos, D. (2010). Factors affecting diclofenac decomposition in water by $\mathrm{UV}-\mathrm{A} / \mathrm{TiO}_{2}$ photocatalysis. Chem. Eng. J. 161, 53-59. DOI: 10.1016/j.cej.2010.04.020.

34. Foo, K.Y. \& Hameed, B.H. (2010). Insights into the modelling of adsorption isotherm systems, Chem. Eng. J. 156, 2-10, DOI: 10.1016/j.cej.2009.09.013.

35. Lekkerkerker-Teunissen, K., Benotti, M.J., Snyder, S.A. \& van Dijk, H.C. (2012). Transformation of atrazine, carbamazepine, diclofenac and sulfamethoxazole by low and medium pressure UV and $\mathrm{UV} / \mathrm{H}_{2} \mathrm{O}_{2}$ treatment. Sep. Purif. Technol. 96, 33-43. DOI: 10.1016/j.seppur.2012.05.005.

36. Calza, P., Sakkas, V.A., Medana, C., Baiocchi, C., Dimou, A., Pelizzetti, E. \& Albanis, T. (2006). Photocatalytic degradation study of diclofenac over aqueous $\mathrm{TiO}_{2}$ suspensions. Appl. Catal. B-Environ. 67, 197-205. DOI: 10.1016/j.apcatb.2006.04.021. 